\title{
Reflexiones en torno a la lucha sindical de SIMETRISSS
}

No sin razón puede afirmarse que, desde la firma de los acuerdos de paz, el pesimismo y la apatía por los aspectos sociales han encontrado un terreno fértil en la sociedad salvadoreña. Ya sea por efecto de la guerra o porque el nuevo escenario democrático no es lo suficientemente atractivo como para llamar a los ciudadanos a asumir la función que en la actual trama les corresponde, la participación social —en todo su amplio abanico de concreciones, irreductibles, por supuesto, a la simple emisión del voto - es un fenómeno en franco proceso de extinción. Se habla aquí, evidentemente, de participación cualitativa; de participación que busca consciente y racionalmente generar cambios en la estructura social.

Ciertamente, el diálogo y la concertación son ingredientes esenciales de la participación ciudadana, pero no la agotan. Existen circunstancias en las que el diálogo o es imposible a priori o se empantana en discusiones estériles y dilatorias; en las que la concertación pretende más esquivar la conflictividad que resolverla. En el actual contexto, en el que sesudos analistas afirman poseer la antorcha con la que se alumbrará el camino para salir de la minoría de edad, en el que comulgar con un ideal de sociedad ya definido es condición sine qua non para ser un ciudadano racional, el diálogo y la concertación parecen estar más orientados a mantener lo obtenido que a potenciar nuevos cambios.

Se enfatiza demasiado en la opción del diálogo y la concertación, sin atender a sus resultados. En una tendencia que se acentúa cada vez más, se llama a participar en un diálogo que, sin ser operativo, se convierte en justificación de opciones y decisiones ya tomadas. Entre los puntos de discusión ya definidos e incuestionables y los resultados ya planeados de antemano, el diálogo es el intermedio destinado a aplacar la culpa en las conciencias democráticas de los participantes.

Se ha perdido de vista que en la participación ciudadana, las acciones de hecho - ahora demonizadas-, siempre que en ellas opere la razón, pueden ser un mecanismo adecuado para producir el cambio. Al margen de la acción violenta, principios como el de la desobediencia civil, llevados a la práctica por Thoreau y Gandhi, han mostrado sus potencialidades de cambio social una vez que el diálogo ha fracasado o se ha vuelto inoperante.

\section{Acciones de hecho}

En los juicios que se han vertido sobre las ya numerosas huelgas de labores convocada por el Sindicato de Médicos Trabajadores del Instituto del Seguro Social (SIMETRISSS), ha pesado sobremanera la falsa noción de participación social mencionada. A pesar de que las negociaciones entre los médicos y la directiva del ISSS se han mantenido durante meses sin ningún resultado concreto, en gran medida debido a la actitud de la directora de la institución; pese a que las exigencias de SIMETRISSS están orientadas a mejorar las atribuladas condiciones de atención del Seguro Social, no se ha dudado en condenar la acción de los médicos.

¿Puede ser calificada la acción del SIMETRISSS 


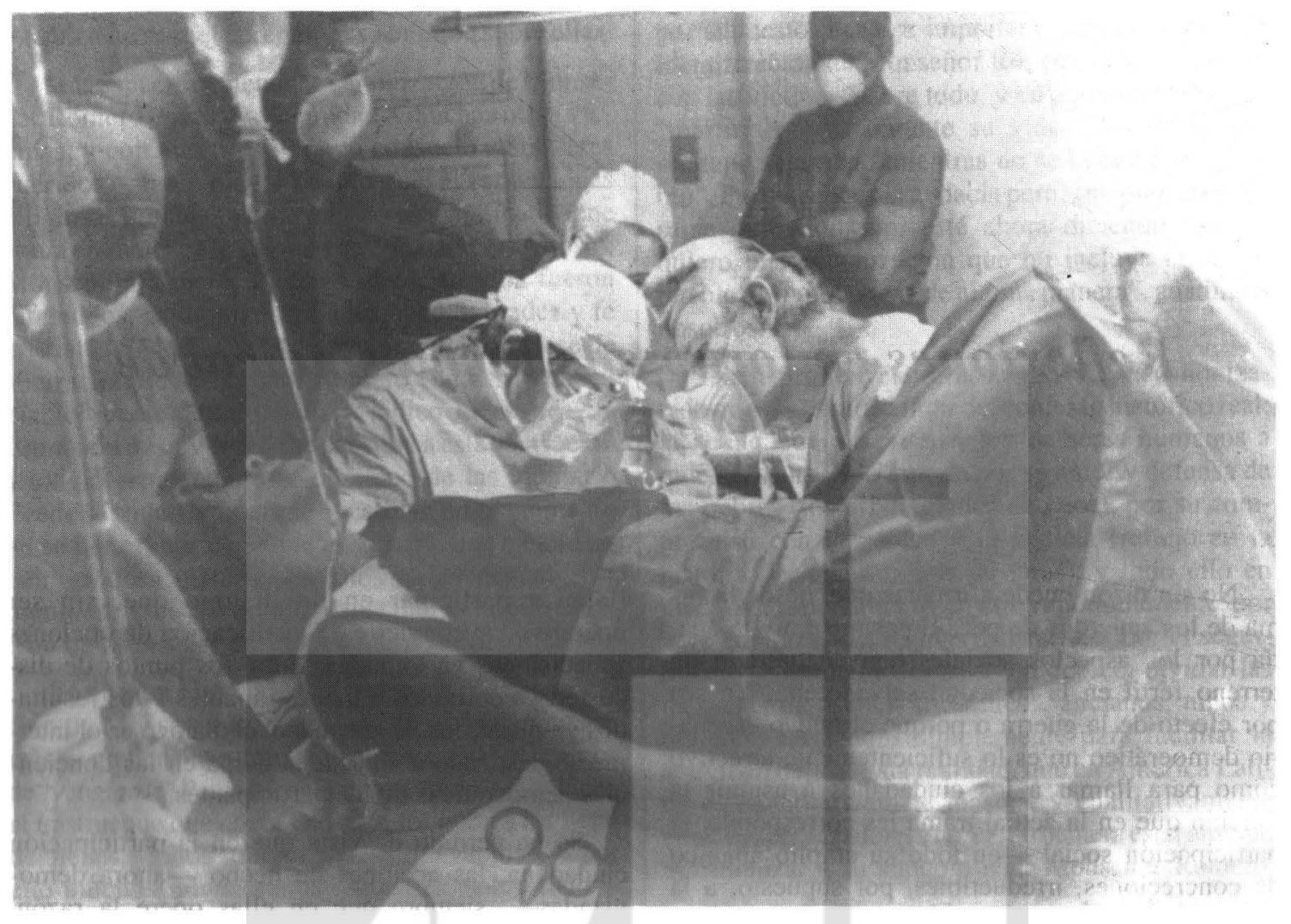

como una manifestación de participación social valedera? El principal elemento que parece estar siendo considerado para responder con una negativa es que los afiliados del Seguro Social están siendo afectados al no poder acceder al servicio de salud. Sin embargo, este razonamiento obvia lo evidente: si con la huelga se logra que se pongan en marcha los mecanismos necesarios para dar cumplimiento a las exigencias de los médicos, la misma población que por ahora se ve obligada a privarse del servicio podrá a futuro gozar de la atención que merece.

Aunque algunos medios sólo hayan hecho énfasis en las exigencias salariales de los médicos, pretendiendo con ello reducir el asunto a una simple cuestión de ambición desmedida, no puede desestimarse que ésta no es la única de las exigencias contenidas en el documento presentado a los directivos del ISSS. Además, debe tomarse en cuenta que una de las razones por las cuales el diálogo se empantanó fue la petición de los médi$\cos$ de que el Seguro Social se abriera a un proce- so de contabilidad que verificará la adecuada asignación de recursos financieros.

Difícilmente puede afirmarse que el recurso de la huelga fue la primera opción de SIMETRISSS para lograr que se escucharan sus peticiones; en especial, si se observa que el primer paro de labores (29 de enero) sólo se dio después de siete meses de infructuosa negociación. Aún más difícil es calificar de irracional su accionar, cuando es precisamente la irracionalidad que ha imperado en el Seguro Social la que pretende ser superada.

Ahora bien, sería desatinado negar tajantemente que tras esta pretensión de SIMETRISSS de perseguir el bien común de los asegurados pueden estar presentes intereses muy particulares. Sin embargo, si para que hubiera una manifestación social en contra de las condiciones bajo las que opera el Seguro Social tendría que haberse esperado la iniciativa de los asegurados, es seguro que la fecha del cambio se habría programado ad calendas graecas. 
A pesar de todos los peros que se puedan poner, la movilización social de SIMETRISSS, incluso con la cuota de sacrilicio que le impone a los asegurados, es una de las más prometedoras que se han dado a lo largo de este año y del anterior. Principalmente porque en ella se expresa lo que pretende ser sepultado con discurso y retórica democrálica: una actilud racionalmente beligerante que no se ve satislecha con el mero hecho de dialogar.

\section{El tercero excluido: los pacientes}

En la encucsta realizada por el Instituto Universitario de Opinión Pública (IUDOP) de la UCA sohre el sistema educativo y la salud (noviembre de 1997), destaca una actitud paradigmática de la ciudadanía hacia los problemas que la aquejan: en buen grado es consciente de que las cosas van mal y de que el gobicrno no se preccupa mucho o no está interesado en solucionarlas. Pero, al mismo tiempo que mantiene una actitud desenladada ante la realidad que la afecta, condena o repudia las acciones sindicales encaminadas a cambiar tal situación anómala.

\section{Gráfica 1 \\ ¿Cómo estará la situación de salud en los próximos años?}

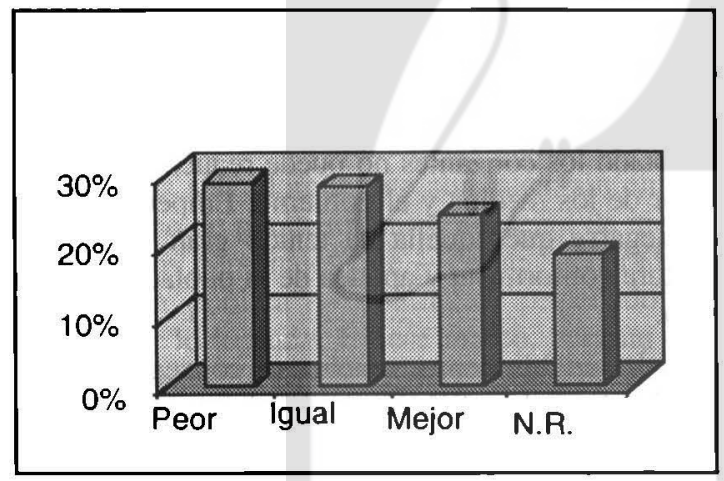

Véanse sino los datos. Según la referida encuesta, un 24.5 por ciento de la población consultada considera que el sistema de salud ha empeorado en comparación con otros años; un 40.4 por ciento percibe que se mantiene igual y tan sólo un 24.5 por ciento evalúa que ha mejorado. En el mismo sentido (ver Gráfica 1), el 29 por ciento de la muestra opinó que la situación de salud empeorará en los próximos años; un 28.5 por ciento piensa que se mantendrá igual y un 24 por ciento, que mejorará. Curiosamente, en contraste con las expectativas de que se opere un cambio positivo en el sistema de salud o de que éste se mantendrá tal como está, $0.2,35.4$ y 30.3 por ciento de la muestra considera, respectivamente, que el gobierno tiene nada, poco o algo de interés en los problemas de salud del país. Es decir, la población, a la vez que nota un detrimento o estancamiento en el sistema de salud salvadoreño —el cual es, a todas luces, deficiente en los servicios que ofrece-considera que el gobierno - en definitiva la instancia responsable de hacer operar los cambios- no tiene gran interés en mejorarlo.

Cuando la encuesta interroga a la muestra sobre su parecer respecto a las acciones sindicales de los empleados del sector salud, específicamente en cuanto a las huelgas realizadas por éstos durante 1997 (ver Gráfica 2), sale a la luz un dato aún más sorprendente: la mayoría, un 53.2 por ciento, se manifiesta en desacuerdo. Recordando que, en las huelgas que desarrollaron los empleados del sector de salud en 1997, la búsqueda de mejoras en las condiciones de atención al público no era explícita, sino más bien derivada de otras exigencias, se puede colegir que la población, en lo relacionado con el tema de la salud, ve con desagrado cualquier acción que implique la suspensión temporal del servicio. Aun cuando se considera que, en lérminos globales, éste no mejora y que no es una prioridad del gobierno conseguirlo. En otras palabras, la situación es la siguicnte: entre continuar recibiendo un servicio mediocre o verse privado de él temporalmente por causa de una acción que busca presionar para que éste mejore, se prefiere optar por lo primero.

Las razones para explicar esta paradoja son muchas: el servicio de salud es demasiado importante como para privarse de él por las razones que sean; los movimientos sindicales, en general, hasta la fecha han carecido de la coherencia y el alcance social necesarios para despertar las simpatías y el apoyo de la población; se carece de un espíritu ciudadano de participación social que le dé sentido al hecho de sacrificarse individualmente en aras de alcanzar beneficios colectivos de largo alcance.

Sin duda alguna, como suele suceder en las situaciones en las que el gobierno ve expuestos sus intereses, durante los últimos tres meses de la lucha sindical de SIMETRISSS, los medios de comunicación social enfilaron sus baterías para apoyar y dar cuerpo a la visión oficial sobre el asunto. A través de insidiosos reportajes en los que se pre- 
Gráfica 2

¿Está de acuerdo o en desacuerdo con las huelgas realizadas

por los empleados del sector salud?

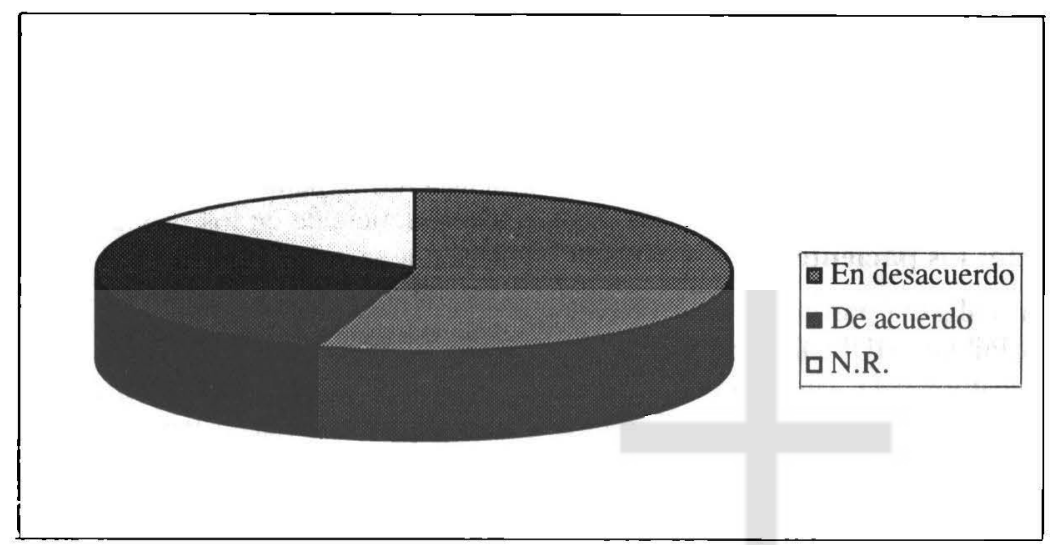

tendía dar cuenta de los desmanes y vejaciones que las huelgas convocadas por SIMETRISSS ocasionaban en los pacientes, se presentaba al sindicato como un grupo que, en pos de demandas puramente económicas, no dudaban en poner en peligro la salud de los derechohabientes.

Además, se reiteraba en que la responsabilidad de las huelgas recaía solamente en el sindicato de médicos, obviando mencionar que las acciones de hecho sólo se habían adoptado luego de meses de infructuosas conversaciones. Sobre lo evidente: que el movimiento persigue lograr cambios en aspectos cruciales del Seguro Social y que por ello ha conseguido el respaldo de un número impresionante -y completamente inusual en el mediode actores y agrupaciones sociales; que la manera en que el gobierno ha respondido ante sus exigencias ha llegado hasta el absurdo (la orden de arresto contra los directivos de SIMETRISSS es su manifestación más grave), sobre lo cual no se ha mencionado una sola palabra.

Sin embargo, para lo que nos interesa, lo preocupante de esta situación no está en el daño moral causado por la campaña de desprestigio emprendida por la prensa en contra de SIMETRISSS, ni en la falsación malintencionada de sus verdaderos objetivos y pretensiones, sino en que, implícitamente, estimula el fortalecimiento de la actitud ya mencionada: desestima o anula el papel que los cotizantes podrían desempeñar en la dinámica. El cotizante sólo es sujeto de la dinámica en tanto que la padece, en tanto que sufre sus consecuencias, sin tener por ello poder de decisión en su desarrollo. Desde esta lógica, entre las demandas de SIMETRISSS y el conglomerado de pacientes no existe ninguna vinculación. Así pues, las acciones del sindicato de médicos sólo le incumben al cotizante en la medida en que el servicio de salud se suspenda; por ello es que es posible que la población asegurada manifieste sin duda su desacuerdo con las huelgas.

Ciertamente, y como ya se mencionó, el desgano de la población en solucionar los problemas que aquejan al servicio de salud no obedece a una sola causa. En este caso, el motivo de la actitud que han adoptado los cotizantes no puede reducirse sólo a la labor de los medios y el gobierno. Empero, no puede negarse que aquélla ha tenido gran peso en la postura conformista y apática de la población asegurada.

Indudablemente, mucho se conseguirá en el Seguro Social si SIMETRISSS logra que la "comisión de alto nivel" resuelva favorablemente sus demandas; más aún si con su desempeño suma a los médicos de salud pública en la búsqueda de mejorar el servicio médico y hospitalario. Pero a nivel de participación social, al nivel de cómo la población entiende y responde ante las dinámicas que la involucran, es difícil, sino imposible, compartir el mismo optimismo. Si no se logra que la ciudadanía participe con algo más que con quejas en la resolución de las problemáticas que le afectan, cualquier logro resultará incompleto.

Marcel Vargas Escolero 